\title{
及2-1 Fructans have a bifidogenic effect in healthy middle-aged human subjects but do not alter immune responses examined in the absence of an in vivo immune challenge: results from a randomised controlled trial
}

\author{
Amy R. Lomax ${ }^{1}$, Lydia V. Y. Cheung ${ }^{1}$, Kieran M. Tuohy ${ }^{\dagger} \dagger$, Paul S. Noakes ${ }^{1}$, Elizabeth A. Miles ${ }^{1}$ \\ and Philip C. Calder ${ }^{1 *}$ \\ ${ }^{1}$ Institute of Human Nutrition and Human Development and Health Academic Unit, Faculty of Medicine, University of \\ Southampton, IDS Building, MP887 Southampton General Hospital, Tremona Road, Southampton SO16 6YD, UK \\ ${ }^{2}$ Food Microbial Sciences Unit, Department of Food and Nutritional Sciences, School of Chemistry, Food Biosciences \\ and Pharmacy, The University of Reading, Whiteknights, Reading RG6 GAP, UK
}

(Submitted 3 August 2011 - Final revision received 30 November 2011 - Accepted 6 December 2011 - First published online 16 January 2012)

\section{Abstract}

$\beta 2-1$ fructans are considered to be prebiotics. Current literature indicates that $\beta 2-1$ fructans may modulate some aspects of immune function, improve the host's ability to respond to certain intestinal infections, and modify some inflammatory outcomes in human subjects. However, there is a need to find out more about the modulation of immune markers by $\beta 2-1$ fructans in humans. Healthy human subjects aged $45-65$ years were randomly allocated to $\beta 2-1$ fructans (Orafti ${ }^{\circledR}$ Synergy $1 ; 8 \mathrm{~g} / \mathrm{d} ; n 22$ ) or the digestible carbohydrate maltodextrin as placebo ( $n$ 21) for 4 weeks. Blood, saliva and faecal samples were collected at study entry and after 4 weeks. Immune parameters were measured using the blood and saliva samples and bifidobacteria were measured in the faecal samples. Faecal bifidobacteria numbers increased in the Orafti ${ }^{\circledR}$ Synergy1 group $(P<0 \cdot 001)$ and were different at 4 weeks from numbers in the placebo group $(P=0.001)$. There was no significant effect of Orafti ${ }^{\circledR}$ Synergy1 on any of the immune parameters measured (blood immune cell subsets, total serum Ig, salivary IgA, neutrophil and monocyte phagocytosis of Escherichia coli and respiratory burst in response to E. coli or phorbol ester, natural killer cell activity, $\mathrm{T}$ cell activation and proliferation, production of six cytokines by $\mathrm{T}$ cells). It is concluded that, compared with maltodextrin, Orafti ${ }^{\circledR}$ Synergy1 has a bifidogenic effect in healthy middle-aged human subjects but does not alter immune responses examined in the absence of an in vivo immune challenge.

Key words: Prebiotics: $\beta 2-1$ Fructans: Immune function: Bifidobacteria

The prebiotic concept has been defined as the selective stimulation of growth and/or activity(ies) of one or a limited number of microbial genus(era)/species in the gut microbiota that confer(s) health benefits to the host ${ }^{(1)}$. $\beta 2-1$ Fructans are considered to be prebiotics. The naturally occurring parent $\beta 2-1$ fructan molecule is inulin. Inulin can vary in chain length, and it can also be digested to lower-molecularweight (shorter-chain-length) molecules. Low-molecularweight $\beta 2-1$ fructans can also be synthesised chemically. Here we refer to both inulin-derived and chemically synthesised short-chain-length $\beta 2-1$ fructans as shorter-chain oligofructose. Orafti ${ }^{\circledR}$ Synergy1 (hereafter referred to as Synergy1) contains a 50:50 (w/w) mixture of long-chain inulin and shorter-chain oligofructose. $\beta 2-1$ Fructans have been reported to modulate the intestinal microbiota, specifically increasing the numbers of bifidobacteria ${ }^{(2-7)}$, lactobacilli $^{(5)}$ and Faecalibacterium prausnitzii ${ }^{(8,9)}$. It is thought that these types of bacteria influence the host immune system, improving its function. Studies performed to date have indicated that $\beta 2-1$ fructan supplementation may modulate aspects of immune function in children ${ }^{(10-13)}$, young adults $^{(14)}$, elderly adults ${ }^{(2,15-19)}$, and adults with colon cancer $^{(20,21)}$, active ulcerative colitis ${ }^{(22)}$ or in an intensive care unit ${ }^{(23)}$. However, many of these studies have combined 32-1 fructans with other nutrients ${ }^{(11,12,14,17-23)}$, and they have evaluated different immune parameters. Therefore, it is difficult to reach a firm conclusion about the impact of $\beta 2-1$ fructans on immune function in humans ${ }^{(24)}$. There are no studies

Abbreviations: CFSE, carboxyfluorescein succinimidyl ester; ConA, concanavalin A; FCS, fetal calf serum; FIFC, fluorescein isothiocyanate; MFI, median fluorescence intensity; PBMC, peripheral blood mononuclear cells; RPMI, Roswell Park Memorial Institute; sIgA, secretory IgA.

*Corresponding author: P. C. Calder, fax +44 2380795255 , email pcc@soton.ac.uk

†Present address: Nutrition and Nutrigenomics Group, Research and Innovation Centre, FEM-IASMA, 38010 San Michele a.A, Trento, Italy. 
of the mixture of inulin and shorter-chain oligofructose, as found in Synergy1, and no studies evaluating the effect of $\beta 2-1$ fructans on immune parameters in healthy middle-aged human subjects. Therefore, the aim of the present study was to evaluate the effect of Synergy1 on faecal bifidobacteria and immune parameters in this target group using a doubleblind randomised controlled trial design with the digestible carbohydrate maltodextrin as placebo. It was anticipated that Synergy 1 would increase faecal bifidobacteria numbers and would enhance some of the immune parameters measured; markers of both innate and acquired immunity were measured.

\section{Subjects, materials and methods \\ Subjects}

Subjects ( $n$ 49) were recruited via posters, word of mouth, email and newspaper/magazine advertisements. The inclusion criteria were as follows: age between 45 and 65 years; BMI between 20 and $32 \mathrm{~kg} / \mathrm{m}^{2}$; not consuming prebiotic or probiotic supplements, drinks or foods; in general good health; no antibiotic use in the 2 months before entering the study or during the study; and not having been vaccinated with the current season's (2008/2009) influenza vaccination; this is because the subjects involved in the study subsequently received this vaccination (data not reported here). Both men and women were recruited. The exclusion criteria were as follows: age $<45$ or $>65$ years; $\mathrm{BMI}<20$ or $>32 \mathrm{~kg} / \mathrm{m}^{2}$; being diabetic (type 1 or type 2 ); displaying manifestations of allergy (asthma, hay fever or dermatitis) or being treated for these; being egg allergic; use of any prescribed medication (unless deemed acceptable by the principal investigator); suffering from any infectious illness or chronic gastrointestinal problem (e.g. irritable bowel syndrome, inflammatory bowel disease, cancer); recent blood donation; participation in another clinical trial; use of prebiotic or probiotic supplement foods or drinks; consuming vitamin, fish oil, evening primrose oil or mineral supplements; previously vaccinated with the 2008/ 2009 vaccination or a previous influenza vaccination which contained any of the strains included in the 2008/2009 vaccine. The study was registered as 'Prebiotics and Immune Function in Middle Aged Humans' on www.clinicaltrials.gov (study identifier: NCT00898599). The study was conducted according to the guidelines laid down in the Declaration of Helsinki and all procedures involving human subjects were approved by the Southampton and South West Hampshire Local Research Ethics Committee (09/H0504/2). Written informed consent was obtained from all subjects. Clinical governance was provided by the Southampton University Hospitals NHS Trust R\&D, and the study was performed according to good clinical practice.

\section{Study design and intervention}

The study was a randomised, double-blind, placebocontrolled trial, with an 8-week intervention period; only data from the first 4 weeks are reported here. Randomisation to the $\beta 2-1$ fructan ( $n$ 25) or placebo (maltodextrin; $n$ 24) group was done by random selection of a sealed envelope containing a treatment code. Unblinding did not occur until after completion of all statistical analyses. Following randomisation, subjects underwent a 2 -week run-in period, during which they limited their consumption of prebiotic- and probiotic-containing foods, and these restrictions continued throughout the study. Upon completion of the run-in period, subjects began the 8-week supplementation period; the start of this period is referred to as week 0 . Synergy 1 and maltodextrin were provided as powders within coded, sealed paper sachets ( $4 \mathrm{~g} /$ sachet) by Beneo-Orafti, and were identical in appearance and packaging, except for the labelling (A or B). Subjects were asked to consume two sachets per d (one in the morning and one in the evening; total intake $8 \mathrm{~g} / \mathrm{d}$ ) by stirring the contents into a glass of water. Subjects were given enough sachets to cover the period of the study; they were asked to return unused and used sachets for assessment of compliance. Subjects attended a clinic at the Wellcome Trust Clinical Research Facility, Southampton General Hospital at weeks 0 and 4 at which blood, saliva and faecal samples were collected; at week 4, the subjects received the 2008/ 2009 seasonal influenza vaccination but data beyond week 4 are not reported here.

\section{Assessment of subjects' self-reported gastrointestinal sensations}

At the clinic visit at week 4 , subjects were verbally asked to report any gastrointestinal sensations or health problems they had encountered in the previous 4 weeks. Specifically, they were asked the question 'Have you noticed any changes in your bowel habits, for example, changes in bowel movements, bloating, gas, unusual pain etc.?'. If they answered 'yes' but did not elaborate, they were asked a second question: 'what changes have you noticed?'.

\section{Enumeration of faecal total bacteria and bifidobacteria}

Frozen $\left(-80^{\circ} \mathrm{C}\right)$ faecal samples collected at the two clinic visits were thawed and then diluted (1:10) in PBS and homogenised in a stomacher for $120 \mathrm{~s}$. The samples were centrifuged at $1500 \mathrm{rpm}$ for $2 \mathrm{~min}$, to separate the liquid and solid matter. An aliquot of the liquid was used to enumerate total bacteria and bifidobacteria. For the total bacteria, the liquid $(375 \mu \mathrm{l})$ was fixed for $4 \mathrm{~h}$ at $4^{\circ} \mathrm{C}$ with $1.125 \mathrm{ml}$ of $4 \%(\mathrm{w} / \mathrm{v})$ paraformaldehyde; the fixed samples were centrifuged at $13000 \mathrm{rpm}$ for 5 min, and washed twice with PBS. The washed cells were resuspended in a mixture of $150 \mu \mathrm{l}$ PBS and $150 \mu \mathrm{l}$ ethanol, and stored at $-20^{\circ} \mathrm{C}$ until further processing. The samples were then diluted in a suitable volume of sterile $\mathrm{PBS} / 10 \%$ SDS in order to obtain an appropriate number of cells per microscopic field of view (a dilution of $1: 400$ or $1: 1000$ ). Then, $20 \mu \mathrm{l}$ of this sample were added to each well of a sixwell slide (Teflon- and poly-L-lysine-coated, six-well, $10 \mathrm{~mm}$ diameter well slides; Tekdon, Inc.). The samples were dried for approximately $15 \mathrm{~min}$ in a drying chamber at $46-50^{\circ} \mathrm{C}$. They were then dehydrated using an alcohol washing series 
(50, 80 and $96 \%(\mathrm{v} / \mathrm{v})$ ethanol) for $3 \mathrm{~min}$ with each solution. Slides were dried for $2 \mathrm{~min}$ at $46-50^{\circ} \mathrm{C}$ to evaporate the excess ethanol. The nucleic acid stain 4',6-diamidino-2-phenylindole $(50 \mathrm{ng} / \mu \mathrm{l})$ was added to PBS at a dilution of $1: 11$, and $50 \mu \mathrm{l}$ of this mixture were applied to each well. The slides were incubated at room temperature in the dark for $15 \mathrm{~min}$ and were then washed in $50 \mathrm{ml}$ of washing buffer $(40 \mathrm{ml}$ double-distilled water, $1 \mathrm{ml}$ of $1 \mathrm{~m}$-Tris- $\mathrm{HCl}(\mathrm{pH} 8.0)$ and $9 \mathrm{ml}$ of $5 \mathrm{M}-\mathrm{NaCl}$ ) for $15 \mathrm{~min}$ at $50^{\circ} \mathrm{C}$. They were then dipped into ice-cold distilled water for $10 \mathrm{~s}$, and dried with compressed air. Then, $5 \mu \mathrm{l}$ of antifade reagent were added to each well, and a coverslip applied to the slide. The slides were stored in the dark at $4^{\circ} \mathrm{C}$ until analysis. The slides were counted using an epifluorescence Brunel microscope. Filters for the 4',6-diamidino-2-phenylindole stain (excitation at $550 \mathrm{~nm}$ and emission at $461 \mathrm{~nm}$ ) and the Cy3 dye (excitation at $550 \mathrm{~nm}$ and emission at $564 \mathrm{~nm}$ ) were used. For each sample, fifteen fields of view were counted. Total bacteria counts were calculated taking into consideration the dilution factors used.

For enumeration of bifidobacteria, samples of the faecal liquid $(375 \mu \mathrm{l})$ were centrifuged at $13000 \mathrm{rpm}$ for $5 \mathrm{~min}$. The cell pellet was resuspended in a mixture of $150 \mu \mathrm{l}$ PBS and $150 \mu \mathrm{l}$ ethanol, and stored at $-20^{\circ} \mathrm{C}$ until further processing. Processing was as described above for total bacteria up to the completion of the ethanol washes of the slides. Then, a synthetic oligonucleotide probe targeting specific regions of the 16S rRNA labelled with the fluorescent dye Cy3 was used for the enumeration of the Bifidobacterium genus (probe: Bif 164, target sequence: CATCCGGCATTACCACCC). $5 \mu \mathrm{l}$ of the probe $(50 \mathrm{ng} / \mu \mathrm{l})$ and $50 \mu \mathrm{l}$ of the hybridisation buffer $(799 \mu \mathrm{l}$ double-distilled water, $20 \mu \mathrm{l}$ of $1 \mathrm{M}$-Tris- $\mathrm{HCl}$ ( $\mathrm{pH} 8.0$ ), $180 \mu \mathrm{l}$ of $5 \mathrm{~m}-\mathrm{NaCl}$ and $1 \mu \mathrm{l}$ SDS) were added to each well and allowed to hybridise for $4 \mathrm{~h}$ in a microarray hybridisation incubator at $50^{\circ} \mathrm{C}$. Following hybridisation, slides were washed in $50 \mathrm{ml}$ of washing buffer $(40 \mathrm{ml}$ double-distilled water, $1 \mathrm{ml}$ of $1 \mathrm{M}$-Tris- $\mathrm{HCl}$ ( $\mathrm{pH} 8 \cdot 0$ ), $9 \mathrm{ml}$ of $5 \mathrm{M}-\mathrm{NaCl}$ and $20 \mu \mathrm{l}$ of $4^{\prime}, 6$-diamidino-2-phenylindole (50 ng/ $\mu \mathrm{l})$ ) for $15 \mathrm{~min}$ at $50^{\circ} \mathrm{C}$. Further processing was as described above for total bacteria.

\section{Measurement of salivary IgA concentration}

Subjects chewed on a dental roll for approximately $30 \mathrm{~s}$. Dental rolls were kept on ice until processing and were then transferred to the barrel of a $5 \mathrm{ml}$ syringe. Saliva was collected by pressure, centrifuged (2000 rpm, $10 \mathrm{~min}$ ) to remove debris, and stored at $-80^{\circ} \mathrm{C}$ until analysis. Secretory IgA (sIgA) concentrations were measured by ELISA (Demeditec). The limit of detection was $1 \mu \mathrm{g} / \mathrm{ml}$. Total salivary protein concentration was measured using the Bradford assay; salivary sIgA concentration is expressed both unadjusted and adjusted for total protein.

\section{Assessment of blood immune cell phenotypes}

Fresh heparinised blood $(100 \mu \mathrm{l})$ was incubated for $30 \mathrm{~min}$ in the dark at $4^{\circ} \mathrm{C}$ with the following fluorescently conjugated antibodies: anti-CD3(fluorescein isothiocyanate (FIFC))/ anti-CD4(RPE) to identify helper T cells; anti-CD3(FITC)/
anti-CD8(RPE) to identify cytotoxic T cells; anti-CD3(FITC)/ anti-CD16(RPE) to identify natural killer cells; antiCD3(FITC)/anti-CD19(RPE) to identify B cells; anti-CD14 (FITC) to identify monocytes; anti-CD4(FITC)/antiCD25(PECy5)/anti-CD127(PE) to identify regulatory $\mathrm{T}$ cells. All antibodies were purchased from AbD Serotec. Following incubation, erythrocytes were lysed (cell lysis buffer; BD Biosciences) and incubated for a further $10 \mathrm{~min}$ in the dark at $4^{\circ} \mathrm{C}$. Samples were then centrifuged (1000 rpm, $7 \mathrm{~min}$ ), and the cells were washed (cell wash solution; BD Biosciences) at $1000 \mathrm{rpm}$ for $7 \mathrm{~min}$. Cells were fixed in $200 \mu \mathrm{l}$ cell fix solution (BD Biosciences), and kept at $4{ }^{\circ} \mathrm{C}$ until analysis by flow cytometry within $48 \mathrm{~h}$. Appropriate isotype controls were always included. Flow cytometry was performed using a Becton Dickinson FACSCalibur fluorescence-activated cell sorter; in all cases, 10000 events were collected. Results were analysed using CellQuest software (BD Biosciences).

\section{Measurement of leucocyte phagocytosis and oxidative burst}

Phagocytosis of Escherichia coli by neutrophils and monocytes and respiratory burst of neutrophils and monocytes in response to E. coli or phorbol myristyl acetate were measured in heparinised whole blood using Phagotest and Phagoburst kits, respectively (both from Orpegen Pharma). In both cases, the manufacturer's instructions were followed. Samples were analysed by flow cytometry on a Becton Dickinson FACSCalibur fluorescence-activated cell sorter and data were collected for 10000 cells. Results were analysed using CellQuest software. The percentage of neutrophils and monocytes performing phagocytosis, the number of ingested bacteria per cell (mean fluorescence intensity), the percentage neutrophils and monocytes producing reactive oxygen metabolites, and the extent of production (mean fluorescence intensity) were all determined.

\section{Serum and peripheral blood mononuclear cell preparation}

Blood $(5 \mathrm{ml})$ was collected into serum tubes and kept at room temperature until processing. The samples were centrifuged (2000 rpm, $10 \mathrm{~min}, 4^{\circ} \mathrm{C}$ ), and serum was stored at $-80^{\circ} \mathrm{C}$ until analysis. Blood $(35 \mathrm{ml})$ was collected into heparin tubes and kept at room temperature until processing. A $2 \mathrm{ml}$ sample of the whole blood was removed and used for immune cell phenotyping, and for the Phagotest and Phagoburst assays (see above). The remaining whole blood was layered onto an equal volume of Histopaque, density $1.077 \mathrm{~g} / \mathrm{ml}$ (Sigma), and centrifuged ( $2000 \mathrm{rpm}, 15 \mathrm{~min}$, room temperature). Peripheral blood mononuclear cells (PBMC) were removed from the interface and washed with Roswell Park Memorial Institute (RPMI)-1640 medium containing $10 \mu \mathrm{g}$ penicillin $/ \mathrm{ml}, 100 \mu \mathrm{g}$ streptomycin $/ \mathrm{ml}$ and $2 \mathrm{~mm}$-glutamine (all from Sigma). The PBMC were then resuspended in RPMI-1640 medium plus 2\% fetal calf serum (FCS; PAA) and washed twice (1200 rpm, 10 min, room temperature). The PBMC were then resuspended in $1 \mathrm{ml}$ RPMI plus $2 \%$ FCS, counted using Trypan Blue staining on a haemocytometer and adjusted to an appropriate cell 
concentration for cryopreservation. An equal volume of freezing medium (FCS plus 15\% dimethyl sulphoxide (Fischer) at $4^{\circ} \mathrm{C}$ ) was added dropwise to the cell suspension on ice to make a final concentration of between $10 \times 10^{6}$ and $25 \times 10^{6}$ cells $/ \mathrm{ml}$. Cells were then stored at $-196^{\circ} \mathrm{C}$ in a liquid $\mathrm{N}_{2}$ tank until use in further experiments. Cryopreserved cells were thawed rapidly in a water-bath at $37^{\circ} \mathrm{C}$. The cells were then placed on ice, and ice-cold RPMI was added dropwise for $1 \mathrm{~min}$ and the volume then made up to $10 \mathrm{ml}$. The cells were centrifuged (1200 rpm, $7 \mathrm{~min}$, room temperature), and then resuspended at a density of $1 \times 10^{6} / \mathrm{ml}$ in RPMI-1640 medium containing $10 \%$ FCS.

\section{Measurement of total serum Ig}

Serum concentrations of IgA, IgM and IgG were measured by ELISA (Zeptometrix for IgA and IgM; Immunodiagnostik for IgG). In all cases, the manufacturers' instructions were followed. Limits of detection were as follows: IgA and IgM $7.8 \mathrm{ng} / \mathrm{ml} ; \operatorname{IgG} 0.32 \mu \mathrm{g} / \mathrm{ml}$.

\section{Measurement of natural killer cell activity}

Natural killer cell activity was determined as killing of the K562 (target) cell line by PBMC. PBMC were used as prepared above and were also pre-incubated with IL-2 $(200 \mathrm{U} / \mathrm{ml})$ for $21 \mathrm{~h}$ at $37^{\circ} \mathrm{C}$ in a $5 \% \mathrm{CO}_{2}$ atmosphere. Target cells $\left(5 \times 10^{6} / \mathrm{ml}\right)$ were incubated with $1.5 \mu \mathrm{l}$ carboxyfluorescein succinimidyl ester (CFSE; $5 \mathrm{mg} / \mathrm{ml}$ final concentration) for $45 \mathrm{~min}$ at $37^{\circ} \mathrm{C}$ in a $5 \% \mathrm{CO}_{2}$ atmosphere. They were then washed and resuspended in RPMI-1640 medium supplemented with 2 mM-glutamine, antibiotics (10 $\mu \mathrm{g}$ penicillin $/ \mathrm{ml}$ and $100 \mu \mathrm{g}$ streptomycin $/ \mathrm{ml})$ and $10 \%$ FCS. Target cells $\left(1 \times 10^{4}\right.$ in a volume of $\left.100 \mu \mathrm{l}\right)$ were then incubated with PBMC at PBMC:target cell ratios of 100:1, $50: 1,25: 1$ and $12 \cdot 5: 1$ and in a total volume of $300 \mu$ l. Incubation was for $2.5 \mathrm{~h}$ at $37^{\circ} \mathrm{C}$ in a $5 \% \mathrm{CO}_{2}$ atmosphere. Cultures without PBMC were included to calculate spontaneous K562 death. After incubation, the cells were collected and transferred to flow cytometry tubes; propidium iodide (final concentration $1 \mathrm{mg} / \mathrm{ml}$ ) was added to each tube. Cells were then analysed by flow cytometry using a Becton Dickinson FACSCalibur fluorescence-activated cell sorter; in all cases, 10000 events were collected. Results were analysed using CellQuest software (BD Biosciences); dead K562 cells were identified as propidium iodide $^{+} \mathrm{CFSE}^{+}$. Specific cell lysis was calculated as (percentage of total target cell death - percentage of spontaneous target cell death).

\section{Measurement of T cell activation by CD69 expression}

Activation of $\mathrm{CD}^{+}$T cells was determined by the appearance of CD69 on the cell surface following stimulation with the T cell mitogen concanavalin A (ConA). PBMC were resuspended at $1 \times 10^{6}$ cells $/ \mathrm{ml}$ in RPMI-1640 medium plus $10 \%$ FCS. They were cultured in ninety-six-well plates for $24 \mathrm{~h}$ at $37^{\circ} \mathrm{C}$ in a $5 \% \quad \mathrm{CO}_{2}$ atmosphere. Total culture volume was $200 \mu \mathrm{l}\left(2 \times 10^{5}\right.$ cells/well $)$, consisting of RPMI-1640 medium supplemented with $2 \mathrm{~mm}$-glutamine, antibiotics
(10 $\mu \mathrm{g}$ penicillin/ml and $100 \mu \mathrm{g}$ streptomycin $/ \mathrm{ml}$ ), 10\% FCS and ConA $(5 \mu \mathrm{g} / \mathrm{ml})$; unstimulated cultures were also performed. After $24 \mathrm{~h}$ of culture, plates were centrifuged (1000 rpm, $10 \mathrm{~min}$ ), and the cells collected. The cells were incubated for $30 \mathrm{~min}$ in the dark at $4^{\circ} \mathrm{C}$ with $10 \mu \mathrm{l}$ antiCD3(FITC)/anti-CD4(RPE) $+5 \mu \mathrm{l}$ anti-CD69(PECy5) or antiCD3(FITC)/anti-CD4(RPE) + $10 \mu \mathrm{l} \operatorname{IgG2a(PECy5)}$ as an isotype control for anti-CD69. The samples were then centrifuged (1000 rpm, $7 \mathrm{~min}$ ), and the cells washed (cell wash solution; BD Biosciences) at $1000 \mathrm{rpm}$ for $7 \mathrm{~min}$. The cells were fixed in $200 \mu \mathrm{l}$ cell fix solution (BD Biosciences), and kept at $4^{\circ} \mathrm{C}$ until analysis by flow cytometry within $48 \mathrm{~h}$. Appropriate isotype controls were always included. Flow cytometry was performed using a Becton Dickinson FACSCalibur fluorescence-activated cell sorter; in all cases, 10000 events were collected. Results were analysed using CellQuest software (BD Biosciences). The percentage of cells that had undergone activation (i.e. $\mathrm{CD}^{+}{ }^{+} \mathrm{CD} 4{ }^{+} \mathrm{CD} 69^{+}$) as well as the median fluorescence intensity (MFI) of CD69 expression on these cells were determined.

\section{Measurement of lymphocyte proliferation by carboxyfluorescein succinimidyl ester dilution}

Proliferation of lymphocytes was determined by the dilution of CFSE following ConA stimulation. PBMC were resuspended at $1 \times 10^{6} \mathrm{cells} / \mathrm{ml}$ in RPMI medium plus $10 \% \mathrm{FCS}$. CFSE stock solution (Molecular Probes) was added to give a final concentration of $10 \mu \mathrm{M}$. Cells were then incubated for $10 \mathrm{~min}$ at $37^{\circ} \mathrm{C}$ in a $5 \% \mathrm{CO}_{2}$ atmosphere. Staining was quenched by adding five volumes of ice-cold medium and incubating the cells on ice for $5 \mathrm{~min}$. The cells were then washed and resuspended at $1 \times 10^{6} / \mathrm{ml}$ in RPMI-1640 medium plus $10 \%$ FCS. They were cultured in ninety-six-well plates for $168 \mathrm{~h}$ at $37^{\circ} \mathrm{C}$ in a $5 \%$ $\mathrm{CO}_{2}$ atmosphere. Total culture volume was $200 \mu \mathrm{l}\left(2 \times 10^{5}\right.$ cells/well), consisting of RPMI-1640 medium supplemented with $2 \mathrm{~mm}$-glutamine, antibiotics $(10 \mu \mathrm{g}$ penicillin/ml and $100 \mu \mathrm{g}$ streptomycin $/ \mathrm{ml}), 10 \%$ FCS and ConA $(5 \mu \mathrm{g} / \mathrm{ml})$; unstimulated cultures were also performed. After $168 \mathrm{~h}$, the cells were collected, transferred to flow cytometry tubes and analysed using a Becton Dickinson FACSCalibur fluorescenceactivated cell sorter. Results were analysed using FlowJo software (Tree Star, Inc.). The percentage of cells that had undergone proliferation as well as CFSE MFI were determined.

\section{Measurement of cytokine production by peripheral blood mononuclear cells}

PBMC were cultured as described above for the measurement of $\mathrm{T}$ cell activation. After $24 \mathrm{~h}$ of culture, the culture plates were centrifuged (1000 rpm, $10 \mathrm{~min}$ ), and the supernatants removed and stored at $-20^{\circ} \mathrm{C}$ until further analysis. Concentrations of IL-2, IL-4, IL-6, IL-10, TNF- $\alpha$ and interferon $\gamma$ were measured using the human Th1/Th2 cytokine kit II (cytometric bead array; BD Biosciences). Culture supernatants $(25 \mu \mathrm{l})$ were added to tubes containing $25 \mu \mathrm{l}$ of the cytokine capture beads and $25 \mu \mathrm{l}$ of detection reagent, and incubated for $3 \mathrm{~h}$. After washing, data were collected on a Becton 
Dickinson FACSCalibur fluorescence-activated cell sorter and captured using CellQuest software. Analysis was performed with FCAP Array software (BD Biosciences). Cytokine standards from a concentration of 0 to $20000 \mathrm{pg} / \mathrm{ml}$ were run in parallel. Limits of detection were as follows: IL-2, $2.6 \mathrm{pg} / \mathrm{ml}$; IL-4, $2 \cdot 6 \mathrm{pg} / \mathrm{ml} ; \quad$ IL- $6, \quad 3.0 \mathrm{pg} / \mathrm{ml} ; \quad$ IL- $10, \quad 2 \cdot 8 \mathrm{pg} / \mathrm{ml} ; \quad \mathrm{TNF}-\alpha$, $2 \cdot 8 \mathrm{pg} / \mathrm{ml}$; interferon $\gamma, 7 \cdot 1 \mathrm{pg} / \mathrm{ml}$.

\section{Statistical analysis}

Comparisons between the groups were performed using the independent samples $t$ test, Mann-Whitney test or $\chi^{2}$ test depending upon the nature of the data. Comparisons between time points within a group were made using the paired $t$ test or Wilcoxon signed-rank test depending upon the nature of the data. Spearman's correlation coefficients were calculated to determine the association between BMI and various outcomes. All analyses were performed using SPSS version 17.0 (SPSS, Inc.), and in all cases, a value of $P<0.05$ was taken to indicate statistical significance.

\section{Results}

\section{Subject characteristics and compliance}

Of the forty-nine subjects recruited and randomised ( $n 24$ in the maltodextrin group; $n 25$ in the prebiotic group), five withdrew before the intervention started. Later, one subject withdrew once the intervention started; this subject was in the prebiotic group and reported inability to tolerate unpleasant gastrointestinal sensations (bloating, unease and feeling urgency to empty bowels). Therefore, forty-three subjects completed the study ( $n 21$ in the maltodextrin group; $n 22$ in the prebiotic group). The characteristics of these subjects did not differ between the groups (Table 1), although there was a trend towards a different balance of sexes between the two groups $(P=0 \cdot 066)$. The proportion of subjects with a BMI of $<25 \mathrm{~kg} / \mathrm{m}^{2}$ did not differ between the two groups ( $52 \%$ in both groups). Compliance, assessed by returned unused sachets, was good in both groups, and ranged from 87 to $101 \%$ (median $100 \%$ ) in the maltodextrin group and 74 to $100 \%$ (median $100 \%$ ) in the prebiotic group.

\section{Self-reported gastrointestinal sensations}

Gastrointestinal sensations reported among subjects who completed the study are shown in Table 2. More subjects in the

Table 1. Subject characteristics according to the study group*

\begin{tabular}{lll}
\hline & Placebo group & Prebiotic group \\
\hline$n$ & 21 & 22 \\
Age (years) & & \\
$\quad$ Mean & 56 & 54 \\
$\quad$ Range & $45-63$ & $45-62$ \\
Male:female & $8: 13$ & $3: 19$ \\
BMl $\left(\mathrm{kg} / \mathrm{m}^{2}\right)$ & & \\
$\quad$ Mean & $25 \cdot 0$ & $25 \cdot 7$ \\
$\quad$ Range & $17 \cdot 7-33.8$ & $19 \cdot 4-33.3$ \\
\hline
\end{tabular}

* Data are shown for subjects who completed the study.
Table 2. Self-reported gastrointestinal sensations in subjects receiving placebo or prebiotic for 4 weeks

(Number of subjects reporting each sensation)

\begin{tabular}{lcc}
\hline Sensation & Placebo group $(n)$ & Prebiotic group $(n)$ \\
\hline Increased bloating & 1 & 2 \\
Decreased bloating & 0 & 1 \\
Increased flatulence & 1 & $12^{\star *}$ \\
Increased regularity of & 2 & $9^{\star}$ \\
$\quad$ bowel movements & 2 & 2 \\
Increased constipation & 0 & 1 \\
Decreased constipation & 0 & 3 \\
Looser stools & & \\
\hline
\end{tabular}

*Values were significantly different from the placebo group ( $\chi^{2}$ test, $P=0.034$ ).

${ }^{*}$ Values were significantly different from the placebo group ( $\chi^{2}$ test, $P=0.001$ ).

prebiotic group reported increased flatulence and increased regularity of bowel movements.

\section{Total bacteria and bifidobacteria}

Fig. 1 shows faecal total bacteria and bifidobacteria numbers in each group at study entry (week 0 ) and after 4 weeks. At week 0 , there were no differences between the groups regarding the number of bifidobacteria (placebo: $1.58 \times 10 \%$ g faeces; prebiotic: $1.33 \times 10^{9} / \mathrm{g}$ faeces), the total number of bacteria (placebo: $0.72 \times 10^{11} / \mathrm{g}$ faeces; prebiotic: $1.01 \times 10^{11} / \mathrm{g}$ faeces) or bifidobacteria expressed as a percentage of total bacteria (average of $1.25 \%$ in both groups). There was no change in total bacteria or bifidobacteria in the placebo group or in total bacteria in the prebiotic group (Fig. 1). However, in the prebiotic group, the number of bifidobacteria was significantly higher $(P<0.001)$ at week $4\left(2.82 \times 10^{9} / \mathrm{g}\right.$ faeces $)$ than at week 0 , and was significantly higher $(P=0 \cdot 001)$ than in the placebo group at week $4\left(1.14 \times 10^{9} / \mathrm{g}\right.$ faeces $)$. The change in bifidobacteria number in the prebiotic group between week 0 and week 4 (median increase $1.26 \times 10^{9} / \mathrm{g}$ faeces) was significantly different $(P=0.001)$ from the change in the placebo group (median increase $3.37 \times 10^{7} / \mathrm{g}$ faeces). Bifidobacteria as a percentage of total bacteria were significantly higher $(P=0 \cdot 001)$ in the prebiotic group at week $4(2.64 \%)$ compared with week 0 . There was a significantly greater $(P=0.002)$ change in bifidobacteria as a percentage of total bacteria in the prebiotic group (median increase $0.84 \%$ ) compared with the placebo group (median increase $0.05 \%$ ).

\section{Blood immune cell phenotypes}

Immune cell phenotypes did not differ between the groups at week 0 (Table 3 ). In the placebo group, the percentage of $\mathrm{CD}^{-} \mathrm{CD}^{-} 6^{+}$cells decreased $(P=0.023)$ and $\mathrm{CD} 14^{+}$cells expressed as a percentage of monocytes increased (63.9$77.9 \%, P=0.020$ ), but this did not occur in the prebiotic group. The percentages of $\mathrm{CD}^{+}{ }^{+} \mathrm{CD} 8^{+}$and $\mathrm{CD}^{+}$cells were higher in the prebiotic group at week 4 compared with the placebo group ( $P=0.032$ and 0.023 , respectively). When comparing the changes over time between the groups, there were no significant differences. Therefore, it must be concluded that the prebiotic supplement had no effect upon immune cell phenotypes in the blood. 
(a)
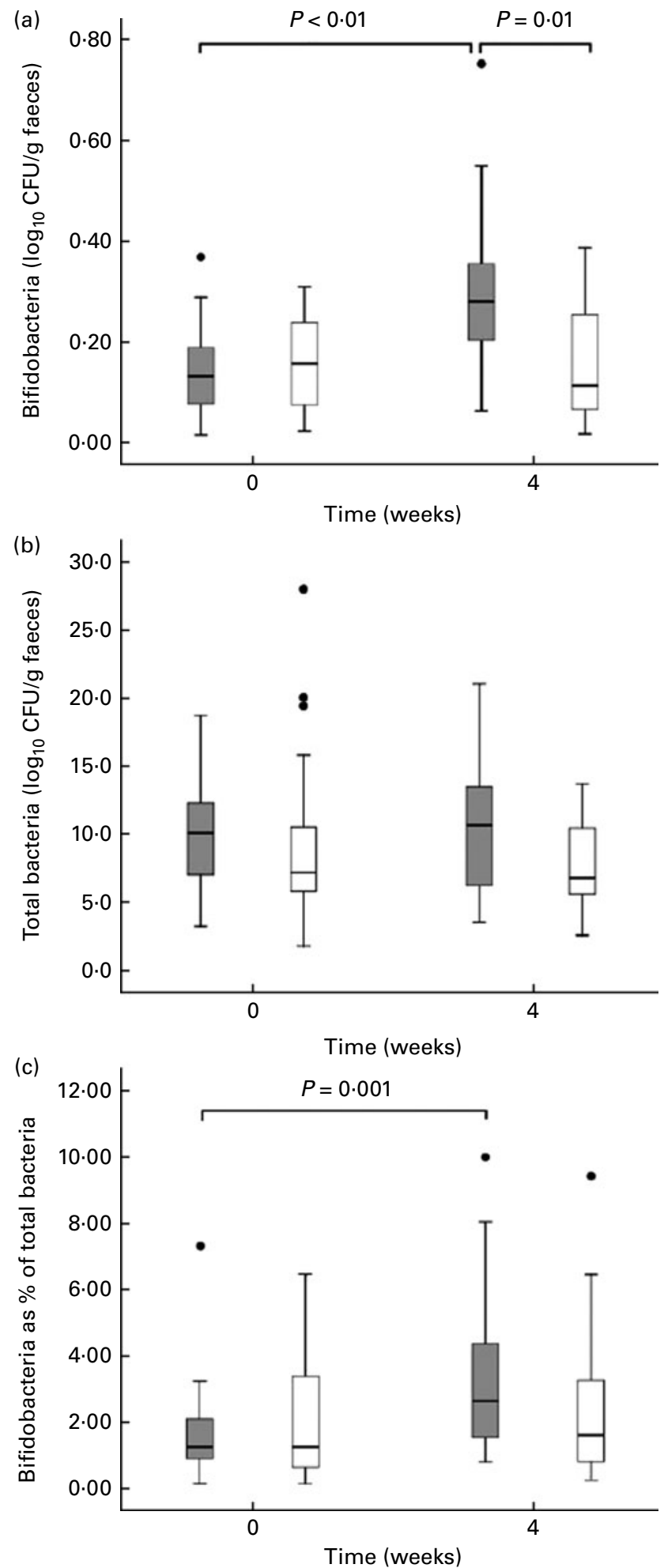

Fig. 1. Faecal bacteria in subjects receiving placebo or prebiotic for 4 weeks. (a) Bifidobacteria; (b) total bacteria; (c) bifidobacteria as a percentage of total bacteria. Box plots show median, first and third quartiles, minimum and maximum values, and outliers. $\square$, Placebo group; $\square$, prebiotic group. Significant differences determined by the Mann-Whitney test and Wilcoxon signed-rank test. CFU, colony-forming units.
Markers of innate immunity: phagocytosis and oxidative burst by neutrophils and monocytes and natural killer cell activity

Data for phagocytosis of $E$. coli by neutrophils and monocytes, respiratory burst by neutrophils and monocytes in response to E. coli or phorbol myristyl acetate, and natural killer cell activity of PBMC towards K562 cells with and without prior incubation with IL-2 are shown in Table 4. Pre-incubation with IL-2 enhanced natural killer cell activity. Although there were changes over time in some of these measures, these changes were similar in both groups, and there were no differences between the two groups at week 0 or week 4 , and there were no differences in the change over time between the groups. Therefore, it must be concluded that the prebiotic supplement had no effect upon these measures of innate immunity.

\section{Markers of humoral immunity: total serum Ig and salivary IgA concentrations}

Serum concentrations of $\operatorname{IgA}, \operatorname{IgG}$ and $\operatorname{IgM}$ and salivary $\operatorname{sgA}$ concentration are shown in Table 5. Although there were changes over time in some of these measures, these changes were similar in both groups, and there were no differences between the two groups at week 0 or week 4 , and there were no differences in the change over time between the groups. Therefore, it must be concluded that the prebiotic supplement had no effect upon these measures of humoral immunity.

\section{Markers of acquired immunity: T cell activation, proliferation and cytokine production}

T cell responses were determined as the expression of the activation marker $\mathrm{CD} 69$ on the surface of $\mathrm{CD} 3^{+} \mathrm{CD} 4^{+}$cells, dilution of the intracellular dye CFSE in response to a mitogenic signal that promotes proliferation, and production of Th1- and Th2type cytokines. The $\mathrm{T}$ cell mitogen ConA was used to elicit these responses. ConA resulted in a marked increase in CD69positive $\mathrm{CD}^{+} \mathrm{CD}^{+}$cells and a marked increase in the level of CD69 expression on those cells (i.e. MFI), a marked increase in the percentage of proliferating $\mathrm{T}$ cells, and a marked reduction in CFSE MFI indicative of dilution of the dye, and a marked increase in the production of all six cytokines assessed (Table 6). Increases were approximately 5 -fold for the percentage of $\mathrm{CD} 9^{+}$cells, approximately 10 -fold for the percentage of proliferating cells, and approximately 5- to 250-fold for cytokine production depending upon the cytokine. There were no differences between the two groups at week 0 or week 4 in any of these measures of $\mathrm{T}$ cell function, and there were no differences in the change over time between the groups. Therefore, it must be concluded that the prebiotic supplement had no effect upon these measures of $\mathrm{T}$ cell function.

\section{Associations between $B M I$ and the reported outcomes and the response to $\beta 2-1$ fructans}

Using data from both groups combined, there was a trend towards an inverse relationship between BMI and bifidobacteria as a 
Table 3. Blood immune cell phenotypes in subjects receiving placebo or prebiotic for 4 weeks (Mean values with their standard errors)

\begin{tabular}{|c|c|c|c|c|c|c|c|c|}
\hline \multirow[b]{3}{*}{ Cell phenotype } & \multicolumn{4}{|c|}{ Placebo group } & \multicolumn{4}{|c|}{ Prebiotic group } \\
\hline & \multicolumn{2}{|c|}{ Week 0} & \multicolumn{2}{|c|}{ Week 4} & \multicolumn{2}{|c|}{ Week 0} & \multicolumn{2}{|c|}{ Week 4} \\
\hline & Mean & SEM & Mean & SEM & Mean & SEM & Mean & SEM \\
\hline $\mathrm{CD}^{+} \mathrm{CD}^{+}(\%$ of lymphocytes $)$ & $50 \cdot 9$ & 8.4 & 50.5 & 6.9 & $50 \cdot 9$ & $6 \cdot 8$ & $50 \cdot 1$ & 8.4 \\
\hline $\mathrm{CD}^{+}(\%$ of lymphocytes $)$ & $51 \cdot 2$ & $8 \cdot 3$ & $50 \cdot 9$ & $7 \cdot 1$ & $51 \cdot 2$ & $6 \cdot 9$ & $50 \cdot 3$ & $8 \cdot 3$ \\
\hline $\mathrm{CD}^{+} \mathrm{CD}^{+}(\%$ of lymphocytes $)$ & 17.9 & 7.5 & $17 \cdot 3$ & $7 \cdot 1$ & $22 \cdot 8$ & $9 \cdot 6$ & $22.9 \dagger$ & 8.9 \\
\hline $\mathrm{CD}^{+}(\%$ of lymphocytes $)$ & $21 \cdot 3$ & $8 \cdot 2$ & 21.0 & 7.4 & $26 \cdot 3$ & $8 \cdot 8$ & $26 \cdot 7 \dagger$ & 8.0 \\
\hline $\mathrm{CD}^{-}{ }^{-} \mathrm{CD} 16^{+}(\%$ of lymphocytes$)$ & $10 \cdot 7$ & $4 \cdot 3$ & $9 \cdot 4^{*}$ & 3.7 & $9 \cdot 6$ & $5 \cdot 6$ & $8 \cdot 2$ & 5.5 \\
\hline $\mathrm{CD}^{-}{ }^{\mathrm{CD}} 19^{+}$(\% of lymphocytes) & $10 \cdot 4$ & 3.5 & $10 \cdot 8$ & 3.7 & 9.4 & 3.7 & $10 \cdot 0$ & 3.9 \\
\hline $\mathrm{CD}_{14}{ }^{+}(\%$ of monocytes $)$ & 63.9 & $24 \cdot 8$ & $77 \cdot 9^{*}$ & $13 \cdot 8$ & 74.7 & $15 \cdot 2$ & $76 \cdot 9$ & $14 \cdot 3$ \\
\hline $\mathrm{CD}_{14}^{+}(\%$ of leucocytes $)$ & $3 \cdot 2$ & 0.9 & 3.6 & 1.5 & $3 \cdot 2$ & 1.0 & 3.2 & 0.6 \\
\hline $\mathrm{CD} 127^{\mathrm{lo}}\left(\%\right.$ of $\mathrm{CD} 4^{+} \mathrm{CD} 25^{+}$cells $)$ & 69.5 & 7.4 & 73.4 & 8.3 & $73 \cdot 8$ & $6 \cdot 8$ & $73 \cdot 1$ & 8.6 \\
\hline $\mathrm{CD}^{+} \mathrm{CD} 25^{+} \mathrm{CD} 127^{\mathrm{lo}}$ (\% of leucocytes) & $1 \cdot 1$ & 0.4 & 1.2 & 0.6 & 1.0 & 0.4 & 1.2 & 0.5 \\
\hline $\mathrm{CD}^{+}: \mathrm{CD}^{+}$ & $2 \cdot 8$ & 1.2 & $2 \cdot 8$ & $1 \cdot 1$ & $2 \cdot 2$ & 0.9 & $2 \cdot 1 \dagger$ & 0.9 \\
\hline
\end{tabular}

$\mathrm{CD} 127^{\text {lo }}, \mathrm{CD} 127^{+}$cells with low fluorescence intensity.

* Mean values were significantly different significantly different from week 0 (paired $t$ test) $(P<0.05)$.

† Mean values were significantly different from the placebo group at the same time point (independent samples $t$ test) $(P<0.05)$.

proportion of total faecal bacteria at week $0(r-0 \cdot 281$, $P=0.092)$, but there was no association with the absolute number of bifidobacteria $(r-0 \cdot 233, P=0 \cdot 166)$. Associations between BMI and the various immune outcomes were explored at week 0. A total of fifty-six associations were explored. Most of these were far from significant, but there were significant associations with the proportion of $\mathrm{CD}^{+} \mathrm{CD} 4^{+} \mathrm{CD} 69^{+}$cells in the bloodstream $(r 0 \cdot 460, P=0.003)$ and CFSE MFI for unstimulated cells $(r 0.329, P=0.033)$. IL-6 production by unstimulated and ConA-stimulated $\mathrm{T}$ cells tended to be positively associated with BMI ( $r 0 \cdot 289, P=0.060$ and $r 0 \cdot 262, P=0 \cdot 090$, respectively).

The change in the various outcomes (i.e. week 4 minus week 0) in the prebiotic group was not different between the subjects with BMI $<25 \mathrm{~kg} / \mathrm{m}^{2}$ and those with BMI $>25 \mathrm{~kg} / \mathrm{m}^{2}$.

\section{Discussion}

There have been several human studies showing that $\beta 2-1$ fructan-type prebiotics may have an impact on immune function $^{(2,10-23)}$. However, these studies have frequently combined the prebiotic with other nutrients ${ }^{(11,12,14,17-23)}$, or have studied infants $^{(10-12)}$ or patients ${ }^{(20-23)}$. It is necessary to identify the functional effects of $\beta 2-1$ fructans on immune function in the absence of co-interventions, and to identify whether effects occur in healthy middle-aged subjects since these are a target consumer population. The present study investigated the effect of Synergy1, a mixture of shorter-chain oligofructose and inulin, at $8 \mathrm{~g} / \mathrm{d}$ for 4 weeks on faecal bifidobacteria and measures of innate, humoral and $\mathrm{T}$ cell-mediated immunity in healthy middle-aged subjects; a randomised controlled parallel study design was used with the digestible carbohydrate maltodextrin as placebo. Compliance to both prebiotic and maltodextrin was good. Subjects in the prebiotic group reported altered gastrointestinal sensations, especially increased gas and regularity of bowel movements. These are suggestive of a change in gut microbiota. While increased flatulence may be unpleasant, increased regularity of bowel movements may be a desirable outcome both personally and clinically ${ }^{(25,26)}$, and has recently been endorsed as a beneficial physiological effect by the European Food Standards Authority $^{(27)}$. Faecal bifidobacteria numbers increased with Synergy1 consumption for 4 weeks. Other studies have previously reported the bifidogenic property of inulin ${ }^{(3-6,28)}$, shorter-chain oligofructose $\mathrm{e}^{(2,7,29)}$ and Synergy ${ }^{(30)}$. In the present study, there was an approximate doubling of faecal bifidobacteria numbers in the Synergy1 group. A similar size of effect has been observed in some studies using inulin ${ }^{(3,4)}$. However, several studies have reported larger increases in bifidobacteria following consumption of $\beta 2-1$ fructans $^{(5-7,29)}$. The increase in bifidobacteria seen in the present study may be smaller in comparison with that seen in some other studies because of differences in the prebiotic dose used, the duration of the intervention, type of $\beta 2-1$ fructan used, the inherent characteristics of the subjects studied and the method used to measure the faecal bifidobacteria.

It was anticipated that Synergy1 would increase faecal bifidobacteria numbers, which was observed to occur, and that this effect would result in some modification of host immune parameters. A range of immune parameters was used in order to identify a potential effect on innate immunity, humoral immunity and T cell-mediated immunity. As a comparator, the digestible carbohydrate maltodextrin was used. No effects of Synergy1 were seen on any immune parameter measured, and it must be concluded that the prebiotic supplement had very little, if any, effect upon systemic immune function in healthy middle-aged adults. However, it is important to note that the data reported herein do not include any responses to exogenous immune stimulation, and these are likely to be more meaningful ${ }^{(31)}$. Previous studies in children $^{(11,13)}$, young adults $^{(14)}$, the elderly ${ }^{(2,16,19)}$, adults with colon cancer ${ }^{(20,21)}$, adults with active ulcerative colitis ${ }^{(22)}$ and adults in intensive care ${ }^{(23)}$ reported effects of $\beta 2-1$ fructans on some aspects of immune function, but not on others, when examined in the absence of an exogenous immune challenge. 
Table 4. Innate immune functions in subjects receiving placebo or prebiotic for 4 weeks (Medians and 25th-75th percentiles)

\begin{tabular}{|c|c|c|c|c|c|c|c|c|}
\hline & \multicolumn{4}{|c|}{ Placebo group } & \multicolumn{4}{|c|}{ Prebiotic group } \\
\hline & \multicolumn{2}{|r|}{ Week 0} & \multicolumn{2}{|r|}{ Week 4} & \multicolumn{2}{|r|}{ Week 0} & \multicolumn{2}{|r|}{ Week 4} \\
\hline & Median & 25th-75th percentiles & Median & 25th-75th percentiles & Median & 25th-75th percentiles & Median & 25th-75th percentiles \\
\hline \multicolumn{9}{|l|}{ Phagocytosis } \\
\hline Neutrophils (\% positive)† & $99 \cdot 1$ & $98 \cdot 1-99 \cdot 5$ & $92 \cdot 9^{*}$ & $82 \cdot 6-96 \cdot 3$ & $99 \cdot 1$ & $94.4-99.5$ & $92 \cdot 2^{\star}$ & $82 \cdot 7-95 \cdot 5$ \\
\hline Neutrophils (MFI) $\dagger$ & 210 & $184-247$ & $334^{*}$ & $228-408$ & 209 & $175-242$ & $243^{*}$ & $191-353$ \\
\hline Monocytes (\% positive)† & 85.6 & $73 \cdot 2-88 \cdot 0$ & $71.9^{\star}$ & $63 \cdot 3-81 \cdot 9$ & 86.5 & $75.5-89.9$ & $67 \cdot 4^{\star}$ & $51 \cdot 2-78 \cdot 4$ \\
\hline Monocytes (MFI)† & 123 & $114-130$ & $195^{\star}$ & $111-348$ & 118 & $111-139$ & 138 & $106-286$ \\
\hline \multicolumn{9}{|l|}{ Oxidative burst } \\
\hline Neutrophils (\% positive)† & $97 \cdot 2$ & $87 \cdot 3-98 \cdot 9$ & $96 \cdot 9$ & $93 \cdot 6-98 \cdot 6$ & $97 \cdot 9$ & $95 \cdot 9-98.5$ & $97 \cdot 1$ & $89 \cdot 9-98 \cdot 1$ \\
\hline Neutrophils (MFI) $\dagger$ & 86 & $75-123$ & $116^{*}$ & $101-134$ & 92 & $75-158$ & 99 & $73-133$ \\
\hline Monocytes (\% positive) $†$ & $79 \cdot 4$ & $74 \cdot 1-85 \cdot 1$ & 76.8 & $67.6-83.6$ & 79.8 & $72 \cdot 9-85.8$ & $76 \cdot 4$ & $67 \cdot 2-82 \cdot 6$ \\
\hline Monocytes (MFI)† & 23 & $20-30$ & $27^{\star}$ & $23-31$ & 24 & $21-28$ & 24 & $22-29$ \\
\hline Neutrophils (\% positive) $\ddagger$ & 98.9 & $98 \cdot 3-99.6$ & $99 \cdot 1$ & $98 \cdot 3-99.7$ & $99 \cdot 4$ & $98 \cdot 4-99.8$ & $99 \cdot 6$ & $99.2-99.9$ \\
\hline Neutrophils (MFI) $\ddagger$ & 281 & $149-361$ & 303 & $220-385$ & 263 & $222-361$ & 280 & $197-379$ \\
\hline Monocytes (\% positive)‡ & 98.9 & $93 \cdot 2-99 \cdot 9$ & $95 \cdot 3$ & $91 \cdot 3-99 \cdot 8$ & 98.4 & $93.9-99.6$ & $97 \cdot 7$ & $87.5-99.6$ \\
\hline Monocytes (MFI) & 37 & $25-48$ & 33 & $25-43$ & 31 & $27-42$ & 33 & $27-49$ \\
\hline \multicolumn{9}{|c|}{ Natural killer cell activity specific cell lysis } \\
\hline E:T 100:1 & $15 \cdot 1$ & $8 \cdot 7-19 \cdot 2$ & $17 \cdot 4$ & $12 \cdot 9-20.9$ & 14.9 & $10 \cdot 5-22 \cdot 7$ & $12 \cdot 3$ & $7 \cdot 1-18 \cdot 1$ \\
\hline E:T 50:1 & $10 \cdot 0$ & $7 \cdot 6-12 \cdot 5$ & $12 \cdot 2$ & $6 \cdot 3-15 \cdot 2$ & $10 \cdot 4$ & $7 \cdot 7-14 \cdot 2$ & 9.5 & $5 \cdot 8-11 \cdot 6$ \\
\hline E:T 25:1 & 6.9 & $4 \cdot 0-7 \cdot 4$ & $6 \cdot 2$ & $4.0-11 \cdot 2$ & $7 \cdot 1$ & $5 \cdot 8-11 \cdot 2$ & $7 \cdot 3$ & $4 \cdot 3-10 \cdot 7$ \\
\hline E:T 12.5:1 & $3 \cdot 6$ & $3 \cdot 0-4 \cdot 7$ & $4 \cdot 8$ & $3 \cdot 3-9 \cdot 3$ & $5 \cdot 3$ & $3 \cdot 7-8 \cdot 2$ & $4 \cdot 1$ & $2 \cdot 6-8 \cdot 4$ \\
\hline E:T 100:1§ & $34 \cdot 1$ & $25 \cdot 3-39 \cdot 3$ & $36 \cdot 8$ & $26 \cdot 2-46 \cdot 6$ & $31 \cdot 2$ & $20 \cdot 6-50 \cdot 3$ & $23 \cdot 4$ & $15 \cdot 3-33 \cdot 9$ \\
\hline E:T 50:1§ & $29 \cdot 1$ & $18 \cdot 8-34.5$ & 25.9 & $15 \cdot 2-34 \cdot 0$ & $22 \cdot 1$ & $11 \cdot 4-42 \cdot 7$ & $16 \cdot 2$ & $6.9-27.5$ \\
\hline E:T 25:1§ & 17.5 & $12 \cdot 0-20 \cdot 2$ & $12 \cdot 8$ & $9 \cdot 3-16.5$ & $22 \cdot 4$ & $6 \cdot 5-26 \cdot 8$ & $10 \cdot 1$ & $4 \cdot 4-39 \cdot 7$ \\
\hline E:T 12.5:1§ & $7 \cdot 7$ & $4.9-11.5$ & 9.4 & $4 \cdot 1-13 \cdot 8$ & 5.9 & $4 \cdot 7-6 \cdot 6$ & $5 \cdot 1$ & $3 \cdot 2-10 \cdot 2$ \\
\hline
\end{tabular}

$\mathrm{MFI}$, median fluorescence intensity; E:T, effector:target cell ratio.

"Significantly different from week 0 (Wilcoxon signed-rank test) $(P<0.05)$.

$\dagger$ In response to Escherichia coli.

łin response to phorbol myristyl acetate. 
Table 5. Serum Ig and salivary IgA concentrations in subjects receiving placebo or prebiotic for 4 weeks (Medians and 25th-75th percentiles))

\begin{tabular}{|c|c|c|c|c|c|c|c|c|}
\hline \multirow[b]{3}{*}{ Serum lgA $(\mathrm{mg} / \mathrm{ml})$} & \multicolumn{4}{|c|}{ Placebo group } & \multicolumn{4}{|c|}{ Prebiotic group } \\
\hline & \multicolumn{2}{|c|}{ Week 0} & \multicolumn{2}{|c|}{ Week 4} & \multicolumn{2}{|c|}{ Week 0} & \multicolumn{2}{|c|}{ Week 4} \\
\hline & $2 \cdot 80$ & $1.64-4.07$ & 2.07 & $1 \cdot 10-3.89$ & 3.74 & $2 \cdot 82-4 \cdot 34$ & $2 \cdot 29^{*}$ & $1.53-3.92$ \\
\hline Serum IgM (mg/ml) & 0.96 & $0.73-1.44$ & $0.90^{*}$ & $0.40-1.07$ & 0.98 & $0.79-1.38$ & $0 \cdot 88^{*}$ & $0.43-1.01$ \\
\hline Serum IgG $(\mathrm{mg} / \mathrm{ml})$ & $16 \cdot 34$ & $12 \cdot 04-30 \cdot 19$ & $27 \cdot 38^{*}$ & $14.69-45.40$ & 20.43 & $10 \cdot 37-30.98$ & $28 \cdot 17$ & $12 \cdot 91-38.42$ \\
\hline Salivary slgA ( $\mu \mathrm{g} / \mu \mathrm{g}$ protein) & $191 \cdot 3$ & $107 \cdot 1-316 \cdot 6$ & $192 \cdot 3$ & $121 \cdot 3-480 \cdot 2$ & $189 \cdot 6$ & $129 \cdot 9-254 \cdot 7$ & $272 \cdot 5$ & $122 \cdot 1-412 \cdot 5$ \\
\hline Salivary slgA $(\mu \mathrm{g} / \mathrm{ml})$ & 257.6 & $185 \cdot 5-324 \cdot 0$ & 233.4 & $160 \cdot 7-316 \cdot 6$ & $187 \cdot 2$ & $134 \cdot 6-279 \cdot 8$ & $180 \cdot 3$ & $128 \cdot 7-279.9$ \\
\hline
\end{tabular}

slgA, secretory $\lg A$.

${ }^{*}$ Median values were significantly different from week 0 (Wilcoxon signed-rank test) $(P<0.05)$.

Since bifidobacteria counts were shown to increase over the 4 -week time period, the lack of effect of Synergy1 on immune function cannot be due to an absence of a prebiotic effect. Several explanations could be offered for the lack of effect of Synergy1 upon systemic immune function in the present study. First, it is possible that the immune system is already functioning optimally in healthy middle-aged adults; the immune system of infants and the elderly may be more sensitive to the effects of prebiotics. Second, the dose of prebiotic may be important, with greater effects probably at higher doses. However, the dose of $8 \mathrm{~g} / \mathrm{d}$ used in the present study is comparable with that used in other studies, which range from 0.88 to $12 \mathrm{~g} / \mathrm{d}$. Third, the type of $\beta 2-1$ fructan used may influence the biological effects seen. As $\beta 2-1$ fructans with different chain lengths are fermented in different parts of the intestine, this may influence any effect they may have on immune function. However, as Synergy1 contains both long-chain inulin and shorter-chain oligofructose, it would be expected to have an effect over different parts of the intestine. Fourth, the sample size of the present study, although comparable with many other studies of this type, is fairly small, and therefore, in a bigger study, significant effects may have been observed. Immune markers vary widely between individuals, and it may be that for some parameters measured, the sample size was not large enough to detect differences between the groups. Fifth, it is also possible that the change in faecal bifidobacteria seen was not large enough to influence host immune function; the extent of the bifidogenic effect will depend upon dose and duration of treatment, the chemical composition of the prebiotic, the age, health status and diet of the subjects. Sixth, bacteria other than bifidobacteria, such as lactobacilli, may be involved in the effect of fructo-oligosaccharides on the host immune system, and numbers of these bacteria may not have been affected in the present study. However, bacteria other than bifidobacteria were not assessed here, and so it is not possible

Table 6. Measures of T cell function in subjects receiving placebo or prebiotic for 4 weeks (Medians and 25th-75th percentiles)

\begin{tabular}{|c|c|c|c|c|c|c|c|c|c|}
\hline & \multirow[b]{2}{*}{ ConA } & \multicolumn{4}{|c|}{ Placebo group } & \multicolumn{4}{|c|}{ Prebiotic group } \\
\hline & & \multicolumn{2}{|c|}{ Week 0} & \multicolumn{2}{|c|}{ Week 4} & \multicolumn{2}{|c|}{ Week 0} & \multicolumn{2}{|c|}{ Week 4} \\
\hline \multicolumn{10}{|l|}{$\mathrm{T}$ cell activation } \\
\hline $\mathrm{CD}^{+}{ }^{+} \mathrm{CD} 4^{+} \mathrm{CD} 69^{+}(\%)$ & - & $11 \cdot 0$ & $8 \cdot 8-18 \cdot 3$ & 11.7 & $7 \cdot 9-18 \cdot 3$ & $18 \cdot 7$ & $10 \cdot 7-24 \cdot 4$ & $12 \cdot 3$ & $8 \cdot 3-20 \cdot 1$ \\
\hline CD69 MFI & - & 42 & $36-47$ & 44 & $36-53$ & 42 & $39-47$ & 43 & $39-49$ \\
\hline $\mathrm{CD}^{+} \mathrm{CD}^{+}{ }^{+} \mathrm{CD}_{69}{ }^{+}(\%)$ & + & 61.6 & $56 \cdot 0-72 \cdot 6$ & $57 \cdot 3$ & $48 \cdot 8-71 \cdot 2$ & $64 \cdot 8$ & $56 \cdot 8-69 \cdot 3$ & $55.9^{*}$ & $52 \cdot 8-65 \cdot 1$ \\
\hline CD69 MFI & + & 101 & $74-125$ & 94 & $73-112$ & 96 & $77-113$ & 87 & $75-113$ \\
\hline \multicolumn{10}{|l|}{$\mathrm{T}$ cell proliferation } \\
\hline Proliferating cells (\%) & - & $8 \cdot 3$ & $5 \cdot 5-15 \cdot 7$ & $8 \cdot 8$ & $4 \cdot 9-19 \cdot 0$ & 7.5 & $4 \cdot 1-15 \cdot 7$ & $8 \cdot 6$ & $5 \cdot 5-14.9$ \\
\hline CFSE MFI & - & 754 & $581-1086$ & 785 & $633-1068$ & 783 & $663-1033$ & 787 & $666-936$ \\
\hline Proliferating cells (\%) & + & 79.6 & $67 \cdot 7-85 \cdot 9$ & 78.1 & $62 \cdot 9-83 \cdot 3$ & $77 \cdot 3$ & $71.5-88.5$ & $75 \cdot 5$ & $67 \cdot 4-86 \cdot 6$ \\
\hline CFSE MFI & + & 160 & $116-210$ & 167 & $132-217$ & 147 & $112-188$ & 162 & $116-195$ \\
\hline \multicolumn{10}{|c|}{ Cytokine concentration (pg/ml) } \\
\hline IL-2 & - & 1.6 & $1 \cdot 3-2 \cdot 1$ & 1.6 & $1 \cdot 3-2 \cdot 1$ & 1.8 & $1 \cdot 3-2 \cdot 7$ & $1 \cdot 8$ & $1 \cdot 3-2 \cdot 2$ \\
\hline IL-4 & - & 1.5 & $1 \cdot 3-2 \cdot 1$ & $1 \cdot 8$ & $1 \cdot 3-2 \cdot 5$ & $1 \cdot 3$ & $1 \cdot 3-1 \cdot 7$ & $1 \cdot 3$ & $1 \cdot 3-1 \cdot 6$ \\
\hline IL-6 & - & 1754 & $687-3294$ & 2275 & $724-3857$ & 1103 & $484-5103$ & 1327 & $518-3390$ \\
\hline IL-10 & - & $12 \cdot 7$ & $9 \cdot 4-20 \cdot 7$ & $18 \cdot 2$ & $5 \cdot 8-21 \cdot 1$ & $14 \cdot 8$ & $8.1-29.7$ & $12 \cdot 1$ & $7 \cdot 9-19 \cdot 0$ \\
\hline TNF- $\alpha$ & - & $29 \cdot 0$ & $10 \cdot 1-47 \cdot 6$ & $30 \cdot 2$ & $10 \cdot 7-57 \cdot 7$ & $36 \cdot 7$ & $4 \cdot 6-50 \cdot 9$ & $23 \cdot 3^{*}$ & $9.4-32.9$ \\
\hline IFN- $\gamma$ & - & 3.6 & $3.6-3.9$ & 3.6 & $3.6-8.6$ & $3 \cdot 6$ & $3 \cdot 6-4 \cdot 7$ & 3.6 & $3 \cdot 6-4 \cdot 4$ \\
\hline IL-2 & + & $76 \cdot 3$ & $52 \cdot 8-152 \cdot 4$ & $65 \cdot 0$ & $45 \cdot 2-127 \cdot 4$ & 79.5 & $60 \cdot 7-177 \cdot 5$ & 84.0 & $58 \cdot 8-154.5$ \\
\hline $\mathrm{IL}-4$ & + & 11.7 & $7 \cdot 6-17.9$ & $9 \cdot 8$ & $6 \cdot 1-15 \cdot 7$ & 8.6 & $5 \cdot 0-9.9$ & 8.2 & $5.5-10.7$ \\
\hline IL-6 & + & 9451 & $4591-11045$ & 7004 & $1978-12521$ & 7764 & $3892-13537$ & 7771 & $6387-10976$ \\
\hline IL-10 & + & $76 \cdot 0$ & $51 \cdot 0-116 \cdot 8$ & 68.3 & $45 \cdot 1-99 \cdot 8$ & $72 \cdot 2$ & $47 \cdot 5-88 \cdot 7$ & 63.5 & $55 \cdot 6-119 \cdot 4$ \\
\hline TNF- $\alpha$ & + & 382.5 & $220 \cdot 1-544.4$ & $292 \cdot 3$ & $152 \cdot 1-477 \cdot 9$ & $306 \cdot 4$ & $164 \cdot 6-574 \cdot 3$ & $360 \cdot 7$ & $89 \cdot 2-566 \cdot 9$ \\
\hline IFN- $\gamma$ & + & 892 & $387-1555$ & 713 & $293-1479$ & 1236 & $397-2314$ & 1210 & $519-2069$ \\
\hline
\end{tabular}

ConA, concanavalin A; MFI, median fluorescence intensity; CFSE, carboxyfluorescein succinimidyl ester; IFN, interferon.

* Median values were significantly different from week 0 (Wilcoxon signed-rank test) $(P<0.05)$. 
to consider this possibility further as an explanation for the lack of immune effects seen. Finally, Synergy1 may alter aspects of the gut-associated immune system. However, no markers of immune function in the gut were measured in the present study that focused upon systemic markers measured in the blood, which may not reflect actions at the gut mucosa. The present study did measure salivary sIgA, but this is more representative of the upper respiratory tract immune system than the gut-associated immune system. Future studies could investigate markers of the gut-associated immune response where these are available. Faecal sIgA has been shown to increase in newborn infants supplemented with a combination of galacto-oligosaccharides and shorterchain oligofructose ${ }^{(11,13)}$. It is also worth noting that a protective effect of $\beta 2-1$ fructans may occur via an alteration in the immunological challenges imposed by a healthier gut microbiota rather than through measurable changes in immune parameters.

Studies have reported a difference in gut microbiota between normal-weight and obese individuals ${ }^{(32,33)}$. Furthermore, obesity is now recognised as a state of chronic low-grade inflammation characterised by elevated circulating concentrations of inflammatory markers including cytokines such as IL- $6{ }^{(34)}$. It is proposed that there is a link between the altered gut microbiota and the low-grade inflammation seen in obesity ${ }^{(35)}$. The present study recruited subjects across a BMI range extending from normal weight, through overweight and into obesity. A post hoc exploration of the relationship between BMI and faecal microbiota indicated a trend towards a lower percentage of bifidobacteria with increasing BMI, but there were few relationships between BMI and the immune parameters measured. However, the present study did not measure circulating concentrations of inflammatory markers. In addition, BMI was found not to result in different effects of Synergy1 on faecal bifidobacteria or the immune functions measured.

In conclusion, the present study shows that consumption of Synergy 1 at $8 \mathrm{~g} / \mathrm{d}$ for 4 weeks increases faecal bifidobacteria and improves regularity of bowel movements in healthy middle-aged adults, effects associated with increased flatulence. However, there are no alterations in a number of markers of systemic innate, humoral and $\mathrm{T}$ cell-mediated immunity measured in the absence of an in vivo immune challenge.

\section{Acknowledgements}

This study was funded by Beneo-Orafti. The authors would like to thank the subjects who took part in the study, and the research nurses at the Wellcome Trust Clinical Research Facility, Southampton General Hospital. The contributions of each author were as follows: A. R. L. recruited the subjects, administered the intervention, processed all blood samples, conducted the laboratory and statistical analyses and drafted the manuscript; L. V. Y. C. conducted the laboratory and statistical analyses; K. M. T. advised on and supervised the laboratory analysis (gut microbiota); P. S. N. conducted and supervised the laboratory analysis; E. A. M. supervised the laboratory analysis; P. C. C. was involved in the study design, overall supervision of all aspects of the study, critical evaluation of the data, final approval of the manuscript. P. C. C. receives consulting fees from Beneo-Orafti. None of the other authors has a conflict of interest.

\section{References}

1. Roberfroid M, Gibson GR, Hoyles L, et al. (2010) Prebiotic effects: metabolic and health benefits. Br J Nutr 104, Suppl. 2, S1-S63.

2. Guigoz Y, Rochat F, Perruisseau-Carrier G, et al. (2002) Effects of oligosaccharide on the faecal flora and nonspecific immune system in elderly people. Nutr Res 22, $13-25$.

3. Fuller Z, Louis P, Mihajlovski A, et al. (2007) Influence of cabbage processing methods and prebiotic manipulation of colonic microflora on glucosinolate breakdown in man. Br J Nutr 98, 364-372.

4. Kolida S, Meyer D \& Gibson GR (2007) A double-blind placebo-controlled study to establish the bifidogenic dose of inulin in healthy humans. Eur J Clin Nutr 61, 1189-1195.

5. Ramnani P, Gaudier E, Bingham M, et al. (2010) Prebiotic effect of fruit and vegetable shots containing Jerusalem artichoke inulin: a human intervention study. Br J Nutr 104, $233-240$.

6. Kleessen B, Schwarz S, Boehm A, et al. (2007) Jerusalem artichoke and chicory inulin in bakery products affect faecal microbiota of healthy volunteers. Br J Nutr 98, 540-549.

7. Tuohy KM, Kolida S, Lustenberger AM, et al. (2001) The prebiotic effects of biscuits containing partially hydrolysed guar gum and fructo-oligosaccharides - a human volunteer study. Br J Nutr 86, 341-348.

8. Ramirez-Farias C, Slezak K, Fuller Z, et al. (2009) Effect of inulin on the human gut microbiota: stimulation of Bifidobacterium adolescentis and Faecalibacterium prausnitzii. Br J Nutr 101, 541-550.

9. Louis P, Young P, Holtrop G, et al. (2010) Diversity of human colonic butyrate-producing bacteria revealed by analysis of the butyryl-CoA:acetate CoA-transferase gene. Environ Microbiol 12, 304-314.

10. Firmansyah A, Pramita G, Carrie-Fassler A, et al. (2001) Improved humoral immune response to measles vaccine in infants receiving infant cereal with fructooligosaccharides. JPGN 31, A521.

11. Bakker-Zierikzee AM, Tol EA, Kroes H, et al. (2006) Faecal SIgA secretion in infants fed on pre- or probiotic infant formula. Pediatr Allergy Immunol 17, 134-140.

12. Moro G, Arslanoglu S, Stahl B, et al. (2006) A mixture of prebiotic oligosaccharids reduces the incidence of atopic dermatitis during the first six months of age. Arch Dis Child 91, 814-819.

13. Scholtens PAMJ, Alliet P, Raes M, et al. (2008) Faecal secretory immunoglobulin A is increased in healthy infants who receive a formula with short-chain galacto-oligosaccharides and long-chain fructo-oligosaccharides. J Nutr 138, 1141-1147.

14. Seidel C, Boehm V, Vogelsang H, et al. (2007) Influence of prebiotics and antioxidants in bread on the immune system, antioxidative status and antioxidative capacity in male smokers and non-smokers. Br J Nut 97, 349-356.

15. Bunout D, Hirsch S, Pia de la Maza M, et al. (2002) Effects of prebiotics on the immune response to vaccination in the elderly. JPEN 26, 372-376.

16. Schiffrin EJ, Thomas DR, Kumar VB, et al. (2007) Systemic inflammatory markers in older persons: the effect of oral 
nutritional supplementation with prebiotics. $J$ Nutr Health Aging 11, 475-479.

17. Langkamp-Henken B, Bender BS, Gardner EM, et al. (2004) Nutritional formula enhanced immune function and reduced days of symptoms of upper respiratory tract infection in seniors. J Am Geriatr Soc 52, 3-12.

18. Langkamp-Henken B, Wood SM, Herrlinger-Garcia KA, et al. (2006) Nutritional formula improved immune profiles of seniors living in nursing homes. J Am Geriatr SOC 54, 1861-1870.

19. Bunout D, Barrera G, Hirsch S, et al. (2004) Effects of a nutritional supplement on the immune response and cytokine production in free-living Chilean elderly. JPEN 28, 348-354.

20. Rafter J, Bennett M, Caderni G, et al. (2007) Dietary synbiotics reduce cancer risk factors in polypectomized and colon cancer patients. Am J Clin Nutr 85, 488-496.

21. Roller M, Clune Y, Collins K, et al. (2007) Consumption of prebiotic inulin enriched with oligofructose in combination with the probiotics Lactobacillus rhamnosus and Bifidobacterium lactis has minor effects on selected immune parameters in polpectomised and colon cancer patients. $\mathrm{Br} J$ Nutr 97, 676-684.

22. Furrie E, Macfarlane S, Kennedy A, et al. (2005) Synbiotic therapy (Bifidobacterium longum/Synergy1) initiates resolution of inflammation in patients with active ulcerative colitis: a randomised controlled pilot trial. Gut 54, 242-249.

23. Kotzampassi K, Giamarellos-Bourboulis EJ, Voudouris A, et al. (2006) Benefits of a synbiotic formula (Synbiotic 2000Forte) in critically Ill trauma patients: early results of a randomized controlled trial. World J Surg 30, 1848-1855.

24. Lomax AR \& Calder PC (2009) Prebiotics, immune function, infection and inflammation: a review of the evidence. $\mathrm{BrJ}$ Nutr 101, 633-658.
25. Cummings JH, Antoine JM, Azpiroz F, et al. (2004) PASSCLAIM - gut health and immunity. Eur J Nutr 43 , Suppl. 2, II118-III73.

26. Van Loo J, Cummings J, Delzenne N, et al. (1999) Functional food properties of non-digestible oligosaccharides: a consensus report from the ENDO project (DGXII AIRII-CT941095). Br J Nutr 81, 121-132.

27. EFSA Panel on Dietetic Products, Nutrition and Allergies (2011) Guidance on the scientific requirements for health claims related to gut and immune function. EFSA J 9, 1984.

28. Meyer D \& Stasse-Wolthuis M (2009) The bifidogenic effect of inulin and oligofructose and its consequences for gut health. Eur J Clin Nutr 63, 1277-1289.

29. Menne E, Guggenbuhl N \& Roberfroid M (2000) Fn-type chicory inulin hydrolysate has a prebiotic effect in humans. J Nutr 130, 1197-1199.

30. De Preter V, Vanhoutte T, Huys G, et al. (2007) Effects of Lactobacillus casei Shirota, Bifidobacterium breve, and oligofructose-enriched inulin on colonic nitrogen-protein metabolism in healthy humans. Am J Physiol Gastrointest Liver Physiol 292, G358-G368.

31. Albers R, Antoine JM, Bourdet-Sicard R, et al. (2005) Markers to measure immunomodulation in human nutrition intervention studies. Br J Nutr 94, 452-481.

32. Flint HJ (2011) Obesity and the gut microbiota. J Clin Gastroenterol 45, S128-S132.

33. Tilg H \& Kaser A (2011) Gut microbiome, obesity, and metabolic dysfunction. J Clin Invest 121, 2126-2132.

34. Calder PC, Ahluwalia N, Brouns F, et al. (2011) Dietary factors and low-grade inflammation in relation to overweight and obesity. Br J Nutr 106, Suppl. S3, S1-S78.

35. Delzenne NM, Neyrinck AM \& Cani PD (2011) Modulation of the gut microbiota by nutrients with prebiotic properties: consequences for host health in the context of obesity and metabolic syndrome. Microb Cell Fact 10, Suppl. 1, S10. 